\title{
Rain Use Efficiency in Southern Romania after Using the Device for Soil Modelling in Interrupted Furrows for Weeding Crops - DMBC-5
}

\author{
Remus Marius Oprescu ${ }^{1}$, Iulian Florin Voicea $^{1 *}$, Iulian Dumitru ${ }^{1}$, Ioana Dragan ${ }^{2}$, Costel \\ Biolan $^{2}$, Nicoleta Ungureanu ${ }^{3}$, Emil Adrian Neagu ${ }^{4}$, Bara Norbert ${ }^{5}$, Daniel Jaloba ${ }^{6}$ and \\ Vlad Nicolae Arsenoaia ${ }^{7}$
}

${ }^{1}$ National Research - Development Institute for Machines and Installations Designed to Agriculture and Food Industry, 6 Ion Ionescu de la Brad Blv., 013813 Bucharest, Sector 1, Romania

${ }^{2}$ AQUAPROIECT, 294 Splaiul Independentei, Bucharest, 060031, Bucharest, Romania

${ }^{3}$ University "POLITEHNICA" Bucharest, Faculty of Biotechnical Systems Engineering, 313 Splaiul Independentei, Bucharest, 060042, Romania

${ }^{4}$ SCDA Mărculeşti, Calarasi, Romania (Agricultural Research and Development Resort Marculesti, Calarasi, Romania)

${ }^{5}$ INCDPM, Bucharest, Romania (The National Institute for Research and Development in Environmental Protection, 294 Splaiul Independentei, 6th District, 060031, Bucharest, Romania)

${ }^{6}$ ICDPP, Bucuresti, Romania (Research - Development Institute for Protection Plant, 8 Ion Ionescu de la Brad Blv., 013813 Bucharest, Sector 1, Romania)

${ }^{7}$ Ion Ionescu de la Brad" University of Agricultural Sciences and Veterinary Medicine, Iasi, Romania (3, Mihail Sadoveanu Alley, Iasi, 700490, Romania)

*Corresponding author:voicea_iulian@yahoo.com

\begin{abstract}
The global impact of climate change, with the potential to affect agriculture through changes in temperature, rainwater distribution and amount, leads to the need to develop integrated technologies that increase rain use efficiency and support soil and environmental quality, ensuring higher agricultural outputs with lower costs. Soil modeling in interrupted furrows is a very efficient rainwater harvesting system, but has not yet been scientifically assessed for the conditions in Southern Romania as the other soil working systems have been. For this purpose, a soil modeling device consisting of a frame with triangle for coupling to the tractor, wheels for adjusting and limiting the working depth, soil loosening knives, ridge ploughs and furrow compartmenting equipment was compared with the conventional technology for sunflower culture in two localities in Southern Romania: Crânguri in Giurgiu County and Mărculești in Calarasi County. The device for soil modeling in interrupted furrows for weeding crops provides a viable option that has positive effects on soil properties and ensures increased crop yields compared to conventional works as well as the opportunity to increase the efficiency of water recovery in agriculture by harvesting rainwater.
\end{abstract}

Keywords: soil modelling; interrupted furrows; water conservation in soil; rain use efficiency. 


\section{Introduction}

In the Southern part of Romania, characterized by a temperate continental climate, there is a need to preserve "in-situ" soil moisture due to insufficient rainfall for agriculture. Cultivated agricultural areas can lose a major part of the rainwater by surface leakage and large amounts of soil through erosion [1]. Rainwater harvesting has the potential to reduce soil erosion and improve the productivity of these areas. Rainwater harvesting is a general term used to describe the collection and concentration of surface leakage for various uses, including for agricultural and domestic use [2].

"In-situ" systems are the simplest and cheapest approaches to harvesting rainwater and can be practiced in many farming systems. Also called water conservation systems, they involve the use of methods to increase the amount of water stored in the soil profile by capturing or retaining precipitation water [3]. A concept on "in-situ" harvesting of rainwater, involving different techniques, is known as "Reservoir tillage" (RT). This approach has been developed taking into account the fact that soil work can increase the storage capacity of surface water and can be one of the most effective means of combating both surface leakage and soil erosion. RT creates basins or cavities to retain water, allowing it to infiltrate the soil and thus prevent leakage [4]. RT was defined by as a system where many small surface depressions are formed to collect and retain rainwater to prevent surface leakage. At present, RT is predominantly used to combat soil erosion in large annual rainfall environments with low intensities. In environments with low and rapid rainfall, as well as with an increase in droughts, interrupted furrows are used to collect precipitation water $[5,9,10,11]$. Through these harvesting works, rainwater is collected in mini-basins, allowing more time for infiltration, which reduces leakage and the potential for erosion and transport of soil particles [6]. In this method, the large infiltration surface created by the depressions and the depth of the water in them lead to higher infiltration rates and thus to a decrease in losses generated by surface leakage and evaporation $[7,12]$. Current scenarios predict that climate change will increase the water deficit in Southern Romania [8]. Climate change has the potential to affect agriculture through changes in temperature, rainwater distribution and amount. Precipitation changes will be one of the most critical factors that will determine the global impact of climate change. This issue indicates the need to develop integrated technologies that increase rain use efficiency and support soil and environment quality, ensuring higher agricultural outputs with lower costs $[11,13]$.

The objective of this study was to develop and evaluate a new technology for soil working with interrupted furrows for weeding crops in the southern area of Romania. The technology includes a soil modeling device to ensure soil loosening and the creation of interrupted furrows on the soil surface for "in situ" harvesting of rainwater.

\section{Materials and Method}

The device for soil modeling in interrupted furrows for weeding crops, simultaneously on 5 intervals, DMBC-5 (Fig.1) is designed for soil modeling in interrupted furrows for weeding crops sown at 70-80 cm, for the accumulation of rainwater and the achievement of a uniform water distribution at the soil surface, on land with a slope of up to $6 \%$, on soils ploughed to a minimum of $250 \mathrm{~mm}$, with light, medium or heavy texture, at a humidity at which the soil does not stick to the active part.

\section{Constructive description of the device}

The device for soil modeling in interrupted furrows for weeding crops, simultaneously on 5 intervals, DMBC-5 consists of the following main parts:

- frame with triangle for coupling to the tractor; 
- wheels for adjusting and limiting the device working depth;

- soil loosening knives before the ridge ploughs;

- ridge ploughs;

- furrow compartmenting equipment.

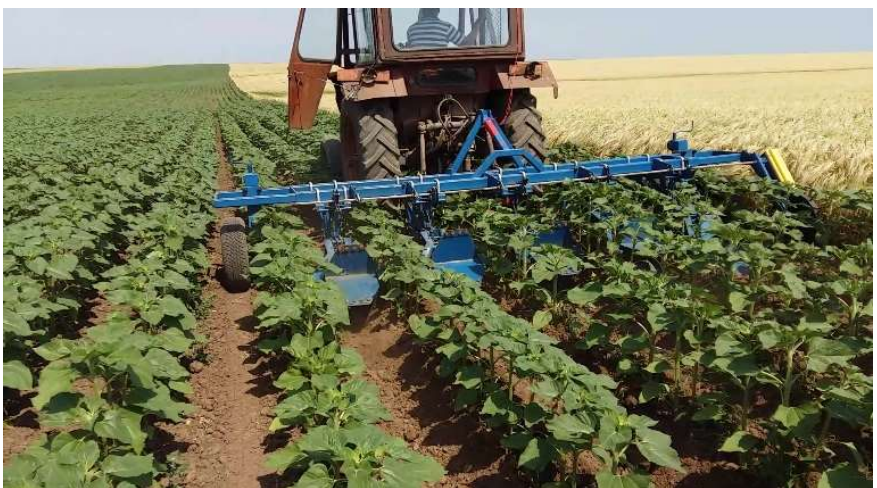

Fig. 1. Device for soil modeling in interrupted furrows for weeding crops, simultaneously on 5 intervals, DMBC-5

The frame of the device is made of two square cross-section pipes, parallel to each other, joined to the ends by welded cross-bars. The three-point tractor coupling triangle (ISO II) is welded to the front of the frame. On the sides of the frame are mounted some removable bars that will increase the working width of the device from $3600 \mathrm{~mm}$ to $5200 \mathrm{~mm}$. Frame clearance will be adjusted according to the plant height by means of supports of loosening knives, respectively of ridge ploughs.

The wheels for adjusting and limiting the working depth are of the metal or rubber tyre type, currently used for soil-working machines, according to the attached documentation or serial production. The wheels have a diameter of $500 \mathrm{~mm}$ and are mounted on the sides of the frame. The working depth of the active parts is continuously adjusted by raising or lowering the wheels by means of a spindle screw actuated by a crank. The lateral removable bars and support wheels are positioned on the frame, respectively on the interval between the plant rows.

A workstation consists of a loosening knife, a ridge plough and an impeller with the control equipment.

The 3, 4 or 5 loosening knives are fastened by means of straps and special cases to the front square pipe. The knives are chisel type and can penetrate into the soil at a depth of maximum $20 \mathrm{~cm}$. The cases allow the knife supports to slide vertically; they can be adjusted to the plant height. Fixing the knife in a certain position is achieved by turning a screw.

The 3, 4 or 5 ridge ploughs have their supports fastened by means of straps and cases, on the second square pipe, behind the loosening knives and are mounted at varying distances on the frame of the device, according to the furrow pattern. The ridge plough consists of a removable knife, a ridge plough bearing support, two breasts and the vertical support. The ridge plough may have mobile or fixed breasts, making a variable or fixed opening. The bearing support, which adjusts the angle of ridge plough penetration into the ground and which is the overload safety element, will be fastened by means of two screws to the ridge plough support. The ridge ploughs are made of properly treated manganese sheet. The ridge plough angle of penetration into the ground can be adjusted by rotating the bearing support against the vertical support. The vertical support, which is a rectangular cross-section bar, is fixed to the second rear bar of the frame with two straps and a case. Adjusting the vertical 
support in the frame fastening case allows the frame to pass over the plants in the weeding crops. When the agricultural machine passes, the plants must not exceed $60 \mathrm{~cm}$ in height in order not to damage them. The active parts (the loosening knives and the ridge plough tip) are hardened and the edges have ensured self-sharpening during operation.

Furrow compartmenting equipment, mounted on the rear bar of the frame, consists of a camshaft, mechanisms for movement transmission to the bolts that lock the impeller blades and 3, 4 or 5 impellers. The rotation movement of the right-side wheel is transmitted by a drive chain to a shaft positioned parallel to the second square bar (rear), shaft that will have some cams positioned next to each work section. During rotation, the camshaft will actuate the lever/cable mechanism from each section in the direction of unlocking the blade with the locking bolt, and by rotating the blade the interruptions will be made; by cyclical unlocking of the rotor, depending on the distance travelled by the device, interruptions will be made at predetermined distances. The rotors will have 4 or 3 trapezoidal blades. The rotors are mounted behind the ridge plough in a frame that allows rotation and oscillation in the vertical plane and they are pressed on the bottom of the furrow with two side-mounted springs or springs that press vertically according to the attached documentation. While the rotation of one of the pallets will be locked by a bolt, it will scrape the bottom and side walls of the furrow, mobilizing a quantity of soil in front of it. When the eccentric cam actuates the lever mechanism, the bolt retracts, releasing the impeller, which rotates one step (the distance between two blades), leaving a soil plug on the furrow, with a base width between 20 and $40 \mathrm{~cm}$ and height equal to the depth of the furrow. While the impeller rotates $90^{\circ}$, the bolt, released by the cam action, returns to the previous position, locking the next rotor blade, and then the cycle restarts. The device provides the modeling of the interrupted watering furrows on the intervals between plant rows in two ways:

- alternatively, a furrow interval and a furrowless interval or

- consecutively, on each interval according to the sowing scheme, the soil type and the root zone of the plant.

The adjustment of the furrow compartmenting equipment allows the creation of soil plugs along the furrow at distances of $1.5 ; 3$ or $6 \mathrm{~m}$.

Dimensional and functional characteristics

- aggregation tractor, HP

- optimal height of plants in the soil modelling phase, $\mathrm{cm}$

$30-60$

- transport clearance, mm

$\min .250$

- frame operational clearance, $\mathrm{mm}$

$\min .500$

- working speed, $\mathrm{km} / \mathrm{h}$

$1.8-3$

- device length, mm

$1500-1700$

- device width, mm

3600 or 5200

- device height, mm

- mass, $\mathrm{kg}$

800

Experiments under exploitation conditions of the DMBC-5 device were carried out in 2018 in two localities (Crânguri in Giurgiu County and Mărculești in Calarasi County), on an alluvial chernozem, respectively on vermic chernozem, in sunflower culture (in cornwheat-sunflower rotation) and comprised a plot where the soil modeling work with interrupted furrows was applied and a control plot worked according to conventional technology. The lands were ploughed in autumn at $30 \mathrm{~cm}$ and in the spring the preparation of the seedbed was done by a superficial work with the combinator and the sowing with a SPC6 seeder. The soil modeling work in interrupted furrows was done when the sunflower crop height in the two localities, Crânguri and Mărculești, was 45.6 , respectively $42.8 \mathrm{~cm}$. In the tests, it was intended to make the interrupted furrows in an area with irregular surface and the adjacent surface was used as a control area. The machine was tested in a 
mechanically hoed area I, on 30 consecutive rows of $866 \mathrm{~m}$ long, $3.5 \mathrm{~m}$ working width, the worked area on a pass was $0.3031 \mathrm{ha} /$ pass, the depth was variable $12-15 \mathrm{~cm}$ depending on the height of the plant, the working speed and the degree of soil compaction. The adjacent control area was also 30 rows, a mechanically hoed zone II and the surface was as irregular as the area tested. The machine was tested in 3 areas representing repetitions of the experiment.

During tests under exploitation conditions, the procedures specific to the soil modeling devices were used and the following metrologically verified measuring and control devices and equipment were used: digital penetrometer with Fieldscout SC900 cone, HH2 portable humidometer with Theta Probe ML2X sensor, mechanical measuring tape, mechanical timer, forrow-meter, rulers, set squares, poles. Soil moisture and compaction at the time of the tests and qualitative working indices for the dimensions of the furrow made by impeller (Fig. 2) were determined.

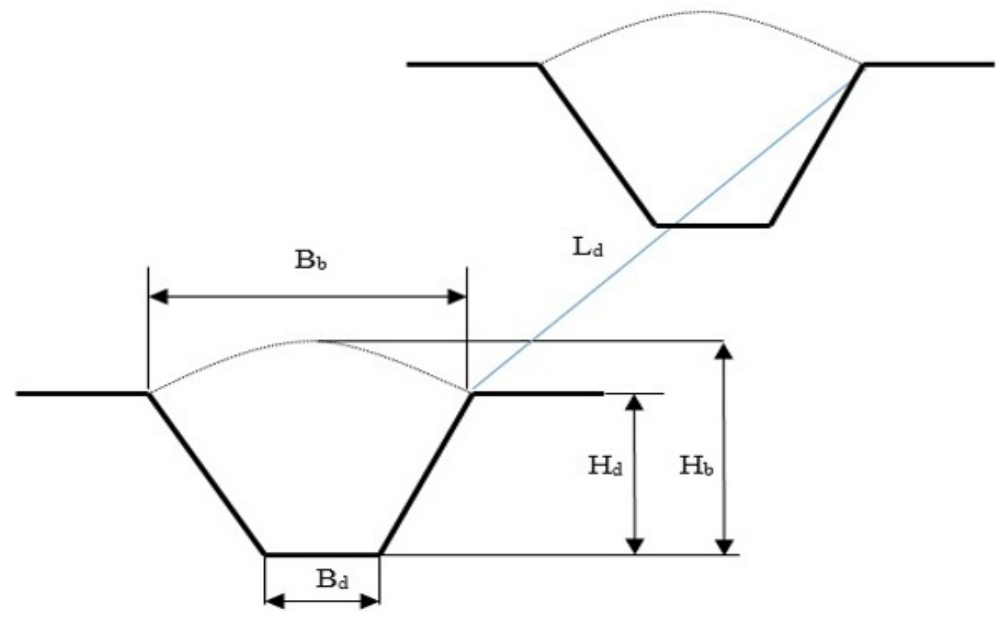

Fig. 2. Dimensions of the furrow made by impeller $(\mathrm{Hb}-$ depth of watering furrows, Bd - width of furrow bottom, $\mathrm{Bb}$ - furrow upper width, $\mathrm{Hd}$ - soil plug height, Ld - plug spacing)

The sunflower crop was harvested at the beginning of the maturation phase when the seed humidity dropped below $15 \%$. Harvesting was done using a harvesting machine equipped with RFS-8 equipment. Production was reported at standardized humidity of $12 \%$. For the assessment of rain use efficiency (RUE), grain production was reported to the precipitation recorded during the vegetation period (April to August) and expressed in $\mathrm{kg} \mathrm{ha}^{-1}$ grains per mm precipitation.

\section{Results}

\subsection{Soil moisture and compaction at the time of testing}

From the analysis of the measured values for compaction (expressed by penetration resistance) and soil moisture it results that in the horizons $0-10 \mathrm{~cm}$ and $10-20 \mathrm{~cm}$ they recorded in Crânguri a significant increase from 100.7 to $153.3 \mathrm{daN} \mathrm{cm}^{-2}$ and from 11.3 to 19.1\% (Fig. 3A).

In Mărculești the penetration resistance indicated a similar evolution, registering on average $74.1 \mathrm{daN} \mathrm{cm}^{-2}$ in the $0-10 \mathrm{~cm}$ horizon and $151.5 \mathrm{daN} \mathrm{cm}^{-2}$ in the $10-20 \mathrm{~cm}$ horizon. This is a significant difference. Humidity recorded an insignificant difference, $11.0 \%$ in the $0-10$ $\mathrm{cm}$ horizon and $12.2 \%$ in the $10-20 \mathrm{~cm}$ horizon (Fig. 3B).

Soil compaction and moisture determined in the lands of the experimental plots of the two localities fall within the agrotechnical requirements of soil modeling works. 

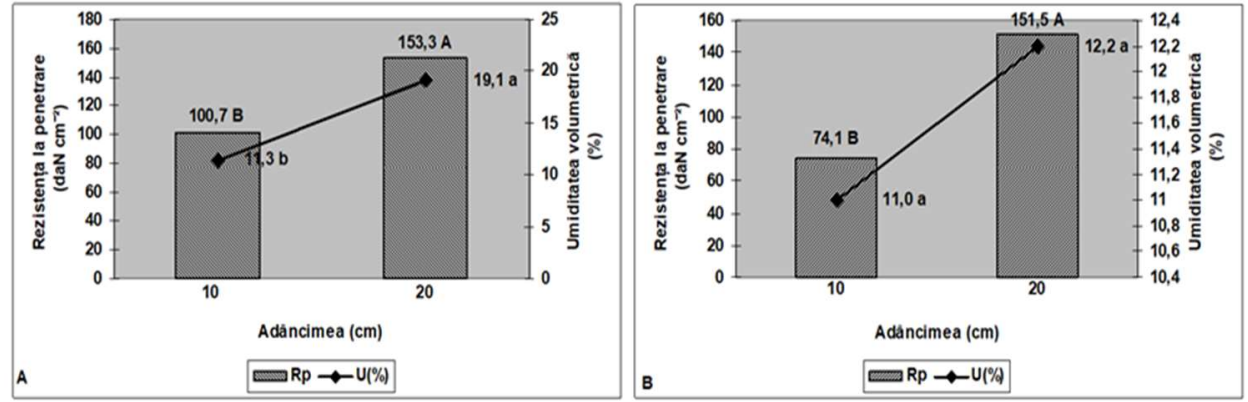

Fig. 3. Land characteristics of experimental lots from Crânguri (A) and Mărculești (B). Different letters indicate significant differences $(\mathrm{p}<0.05)$.

\subsection{Qualitative working indices for the dimensions of the furrow made by DMBC-5 device impeller}

Following the experiments made according to the standards in force, in the two localities, it resulted that the qualitative working indices achieved fall within the agrotechnical requirements of soil modelling works (Fig. 4).
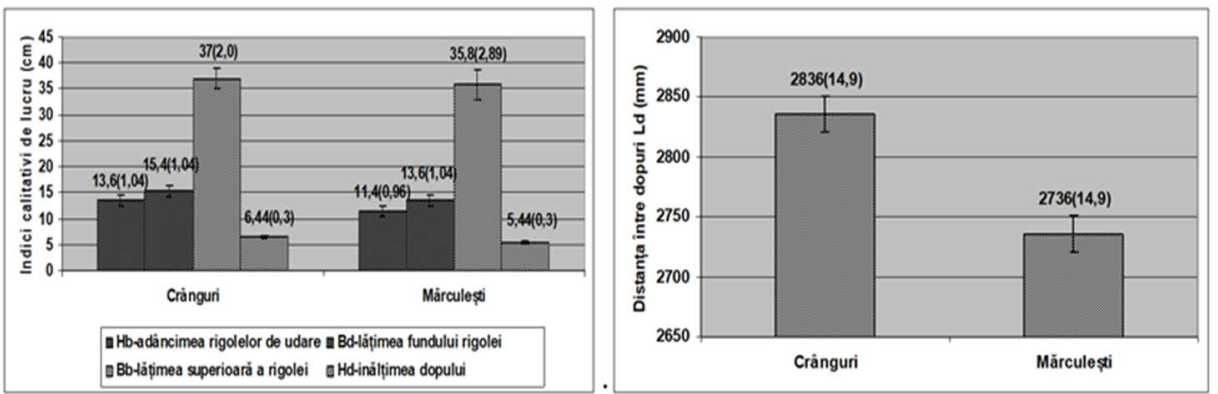

Fig. 4. Qualitative working indices obtained on the sunflower surfaces cultivated in Crânguri and Mărculești in 2018. The values in brackets represent the standard deviations

Thus, for the depth of watering furrows $(\mathrm{Hb})$, furrow upper width $(\mathrm{Bb})$, width of furrow bottom $(\mathrm{Bd})$ and soil plug height $(\mathrm{Hd})$ the coefficients of variation $(\mathrm{CV})$ recorded values below $10 \%$, while for plug spacing (Ld) the CV were less than $5 \%$ according to the requirements of the interrupted furrow works.

\subsection{Sunflower production and rain use efficiency}

In both localities where experiments were carried out, sunflower production was significantly influenced by the soil tillage technology used. The interrupted furrow technology (IFT) provided, compared to conventional technology (CT), an increase of 265 kg ha ${ }^{-1}$ in Crânguri and $319 \mathrm{~kg}$ ha in Mărculești (Fig. 5). 

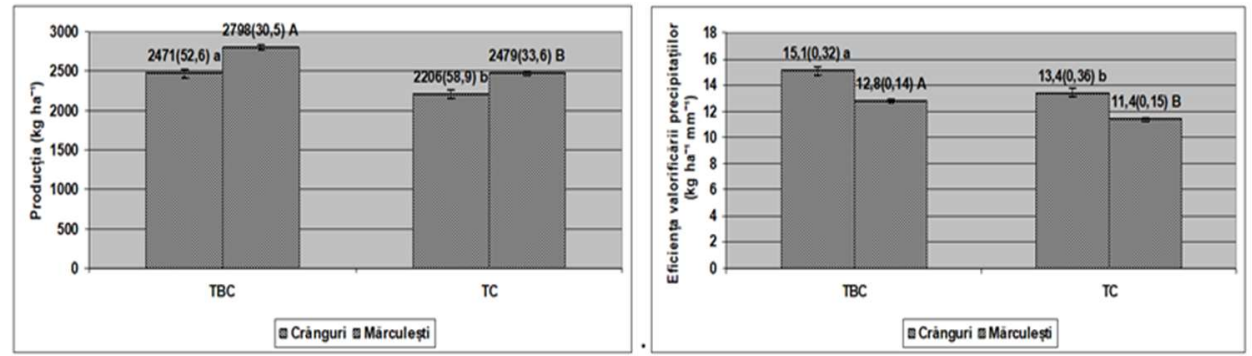

Fig. 5. The sunflower production and rain use efficiency obtained in the two technologies in Crânguri and Mărculești in 2018. The values in brackets represent the standard deviations. Different letters indicate significant differences $(\mathrm{p}<0.05)$.

Figure 5 shows that rain use efficiency (RUE) increased clearly significantly in the two localities in IFT compared to CT. Thus, in Crânguri RUE increased from $13.4 \mathrm{~kg} \mathrm{ha}^{-1}$ $\mathrm{mm}^{-1}$ in CT to $15.1 \mathrm{~kg} \mathrm{ha}^{-1} \mathrm{~mm}^{-1}$ in IFT, respectively in Mărculești from $11.4 \mathrm{~kg} \mathrm{ha}^{-1} \mathrm{~mm}^{-1}$ to $12.8 \mathrm{~kg} \mathrm{ha}^{-1} \mathrm{~mm}^{-1}$.

\section{Conclusions}

By promoting this technology with the new device for soil modeling in interrupted furrows for weeding crops (DMBC-5), it is ensured:

- water conservation in the soil by reducing evaporation in the root zone;

- elimination of the second hoeing;

- weed control in the area of the row between plants, and

- increase of agricultural production by over $10 \%$ as well as of rain use efficiency by over $1,4 \mathrm{~kg} \mathrm{ha}^{-1}$ for every $\mathrm{mm}$ of precipitation.

\section{Acknowledgement}

This work was supported by a grant of the Romanian Research and Innovation Ministry, through Programme 1 - Development of the national research-development system, subprogramme 1.2 - Institutional performance - Projects for financing excellence in RDI, contract no. 16PFE.

\section{References}

[1]. F.L. Duley, Soil Sci. Soc. Am. 4, 60 (1940).

[2]. FAO, Soils Bulletin 69. Rome (1993)

[3]. G. Brhane, C.S. Wortmann, M. Marno, H. Gebrekidan, A. Belay, Agron. J. 98, pp.124134 (2006)

[4]. E.W. Rochester, D.T. Hill, K.H. Yoo, Trans. ASABE 37, pp.1183-1192 (1994)

[5]. M. Kronen, Soil Tillage Res. 32, pp.71-123 (1994)

[6]. E. Ventura, L.D. Norton, K. Ward, M. Lopez-Bautista, A. Tapia-Naranjo,.ASAE Annual Meeting ASABE (2005)

[7]. C. Patrick, C. Kechavarzi, I.T. James, M.O. Dogherty, R.J. Godwin, Soil Use Manage. 23, pp.185-197 (2007)

[8]. A.C. Marica, A. Busuioc, Romanian J. Meteor. 6, pp.50-57(2004). 
[9] T. Sampathkumar, B. Pandian, M. Rangaswamy, P. Manickasundaram, Influence of deficit irrigation on growth, yield and yield parameters of cotton-maize cropping sequence, Agricult. Water Manag., 130, pp. 90-102 (2013).

[10]. N. Korresa, R. Nilda, T. Burgosallias, T. Vurroc, K. Gitsopoulosd, K. Vijaya, O. Stephen, P. Dukef, C. Brabhama, E. Christopher, R Rouseh, P. Salas, New directions for integrated weed management: Modern technologies, tools and knowledge discovery, Adv. in Agron., 4, pp.245-258 (2019).

[11]. R Oprescu., S. Şt. Biriş, E. Marin, C. Sorică, N. Ungureanu, E. Sorică, I. Dumitru, Considerations on mechanically active equipment for open intrrerupted furrow used in technology of weeding plant cultures fruit and viticultural plantations., , pag. $215-220$, ISB-INMA TEH - International Symposium - Agricultural And Mechanical Engineering, Print: ISSN 2344 - 4118, pp. 215-220 (2017).

[12]. R. Oprescu, S. Șt. Biriș, I. Voicea, D. Cujbescu, C. Persu, I. Găgeanu, V. Vlăduţ, I. Dumitru, Considerations on the construction and operation of a device for soil modelling in interrupted furrows for weeding crops, 7 th International Conference on Thermal Equipment, Renewable Energy and Rural Development TE-RE-RD, ISSN 2457 - 3302, pp. 309-315 (2018).

[13]. R. Oprescu, S.Şt. Biriş, I. Voicea, V. Vlăduț, Considerations regarding the construction and operation of an equipment designed to model the soil in compartmented furrows in vineyards and orchards, ISBINMATEH - International Symposium Agricultural And Mechanical Engineering, Print: ISSN 2344 - 4118, pp. 431-436 (2018). 